\title{
Experimental Studies on the Bonding Strength and Fracture Behavior of Incompatible Materials Bonded by Mechanical Adhesion in Multilayer Rotational Molding
}

\author{
Martin Löhner and Dietmar Drummer \\ Institute of Polymer Technology, Friedrich-Alexander-Universität Erlangen-Nürnberg (FAU), Am Weichselgarten 9, \\ 91058 Erlangen, Germany
}

Correspondence should be addressed to Martin Löhner; loehner@lkt.uni-erlangen.de

Received 11 July 2016; Accepted 1 November 2016

Academic Editor: Cornelia Vasile

Copyright (C) 2016 M. Löhner and D. Drummer. This is an open access article distributed under the Creative Commons Attribution License, which permits unrestricted use, distribution, and reproduction in any medium, provided the original work is properly cited.

\begin{abstract}
Rotational molding is a plastic processing method that allows for the production of seamless, hollow parts. Defined shaping of the polymeric material only takes place on the outer surface where contact to the tooling is given. The inner surface forms by surface tension effects. By sequential adding of materials, complex multilayer build-up is possible. Besides pure, single materials, filled, or multiphase systems can be processed as well. In this work, possibilities to generate bonding between supposedly incompatible materials by adding a mix-material interlayer are investigated. Interlock mechanisms on a microscale dimension occur and result in mechanical bonding between the used materials, polyethylene (PE) and thermoplastic polyurethane (TPE-U). The bonding strength between the materials was investigated to reveal the correlations between processing parameters, resulting layer build-up, and bonding strength. The failure behavior was analyzed and inferences to the influence of the varied parameters were drawn.
\end{abstract}

\section{Introduction/Motivation}

Rotational molding is a plastic processing technique which was developed approximately in the 1940s [1]. A hollow mold is filled with plastic in powdery or liquid form in the first process step before the mold starts rotating along two axes which are generally arranged perpendicular to each other. While maintaining the rotation, the mold is heated up in the second process step. This is usually accomplished by convection within an oven. While heating the polymer, it successively melts inside the mold and forms a homogenous porous layer of polymer melt at the inner mold surface. The melting of the particles takes place after adhering to the mold wall and the porous layer is densified while the polymer is kept in the melt state. In the third step the still rotating mold is cooled down by compressed air or water which is applied to the outer mold surface. The polymer solidifies within the mold and forms a solid hollow body. After reaching the demolding temperature, the mold is opened and the part is demolded in the last process step. These process steps of rotational molding are shown in Figure 1.
Large volume, hollow parts are typical applications for rotational molding processes. The process enables the production of seamless hollow bodies with a high degree of design freedom and with very low residual stresses. Kayaks, traffic barriers, and storage tanks with a volume up to 100,000 liters are typical application $[2,3]$.

A total of $85 \%-90 \%$ of the materials processed by rotational molding are devoted to the different PE types [4]. This is on one hand based on historical developments and on the other hand PE fulfills the material requirements of the rotational molding process, such as good followability and a high resistance to thermal degradation. Other materials used are polypropylene (PP), polyvinylchloride (PVC), polyamide (PA), and polycarbonate (PC) [1-5].

The melting and densification processes during rotational molding were analyzed by Kontopoulou and Vlachopoulos [6]. These processes are schematically shown in Figure 2.

The melting process starts with polymer powder particles adhering to the mold wall the temperature of which is above the melting temperature of the polymer (step 1). These powder particles plasticize after reaching the melting temperature 


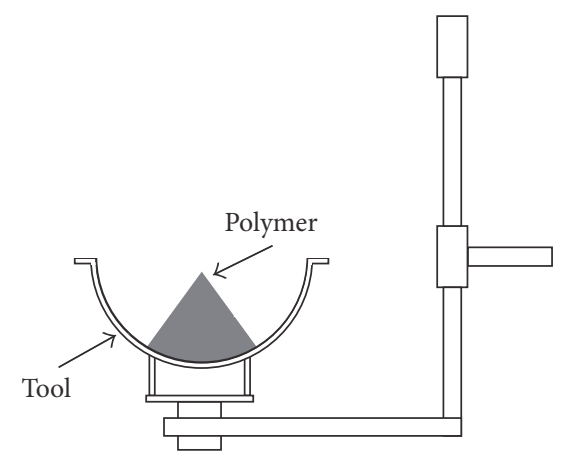

(1) Filling

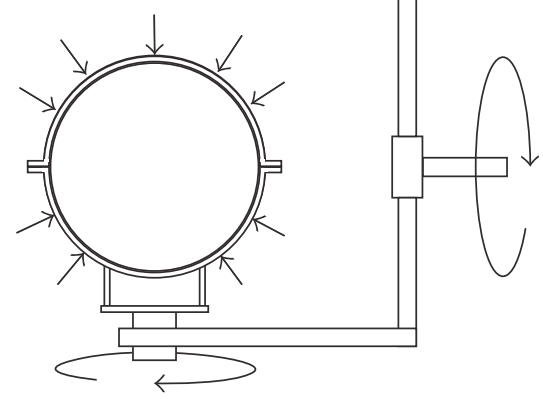

(3) Rotation and cooling

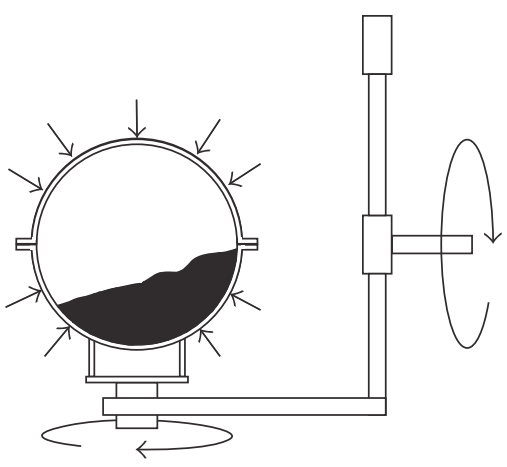

(2) Rotation and heating

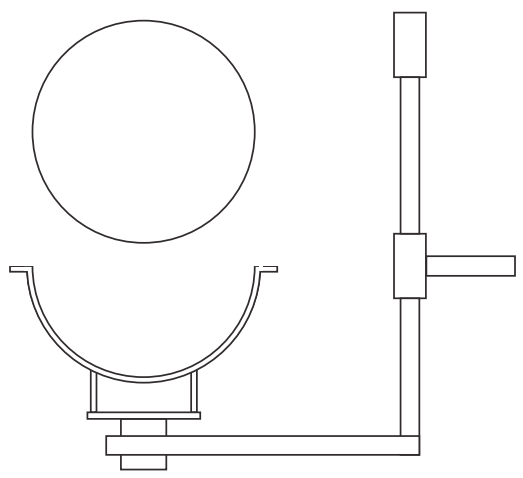

(4) Demolding

FIgURE 1: Process steps of rotational molding (according to [1]).

1

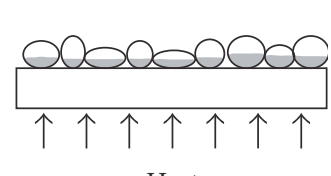

Heat

5

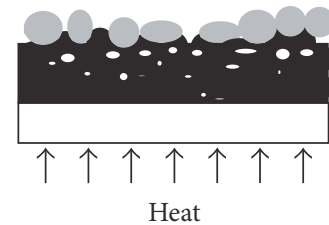

2

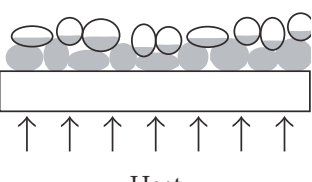

Heat

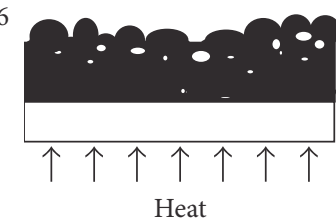

3

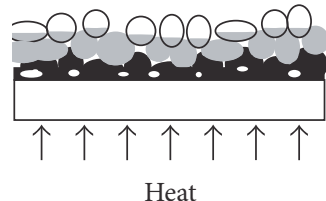

7

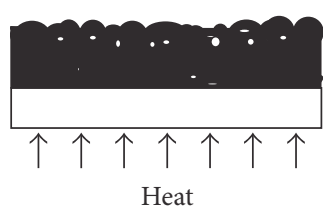

4

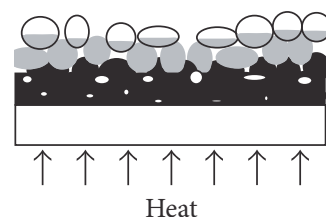

8

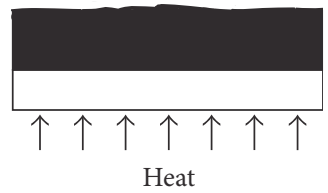

Adhering powder particles

Polymer melt including air bubbles

Plasticized powder particles

Polymer melt without air bubbles

FIGURE 2: Melting and densification process in rotational molding (according to [6, 7]).

of the polymer followed by more powder particles adhering to the plasticized surface of these particles (step 2). Free powder particles flow inside the mold during these process steps until the whole powder adheres to the mold wall (step 4). The plasticized powder particles start to melt with increasing temperature and successively form a homogenous layer of polymer melt (steps 3-5). By maintaining an elevated temperature, the surface of the melt layer becomes uniform and trapped gas inclusions dissolve into the polymer melt (step 6-7). The mentioned mechanisms of the build-up and solution of gas inclusions can be influenced significantly by a suited pressure control $[2,7]$. 
In rotational molding no relevant melt flow appears. The polymeric powder particles melt after adhering to the mold wall and form a melt layer. Due to the absence of shear stresses during processing, the polymeric material stays at the exact location where it first adhered.

Multilayer rotational molding can be achieved by sequential adding of materials to the mold. Different techniques were developed to implement this sequential material adding such as drop boxes $[8,9]$ and the usage of thermoplastic bags containing the second, inner material [10]. Additionally, possibilities for simultaneous adding were investigated [10, 11], where the layerwise arrangement depends on the segregation of the different materials during processing.

Sakaki et al. [12] investigated the adhesion of multilayer parts with a polyethylene and a polypropylene layer and an interlayer consisting of a material mix. The PE density within the blended interlayer was varied and the resulting peel strength was characterized. The peel strength was improved significantly upon integration of an interlayer. Publications investigating the influence of different geometries and processing parameters on the resulting adhesion of multilayer parts with a blended interlayer are not available as of now. Comparable investigations were also conducted with the material combination PE-PA. Here the focus was on the effect of the processing parameters rotation speed, interlayer composition, and interlayer thickness [13].

In general different mechanisms can lead to bonding between two polymers. These bonding mechanisms can be classified as follows [14, 15].

Specific Adhesion. Chemical, physical, and thermodynamical phenomena lead to the adhesion between different materials. Examples for specific adhesion phenomena are Van-derWaals forces, covalent bonds, hydrogen bonds, and diffusion of polymer chains between the joining members. Specific adhesion is strongly dependent on the compatibility of the joining partners.

Mechanical Bonding. Mechanical bonding is mostly independent of the joining members and arises from mechanical grouting originating in undercuts and entanglements between the bonded parts. Mechanical bonding is a formclosure effect, where no specific adhesion between the materials is necessary.

In this work, adhesion is generated within a blended interlayer. According to IUPAC [16] polymer blends are defined as follows: "Macroscopically homogeneous mixture of two or more different species of polymer," whereas, in most cases, blends are homogeneous on scales larger than several times the wavelengths of visible light. The separation of the single components in polymer blends was investigated in various studies. A theoretical approach was first implemented by Cahn and Hilliard for metal alloys [17] which was adapted to polymer blends in several investigations [1820]. In early stages, concentration fluctuations which occur during quenching of blends become unstable and grow [21]. In later stages of phase separation, the effect is mainly driven by diffusion and surface tension [22]. Gelles and Frank [23] investigated the influence of molecular weight on the

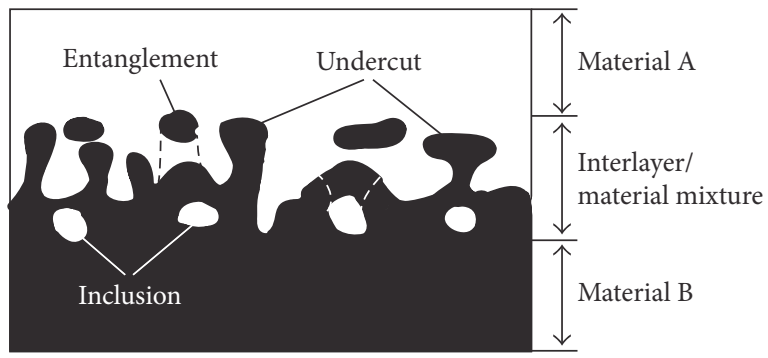

FIGURE 3: Investigated layer setup and occurring material interactions within the interlayer.

separation speed. Higher molecular weights led to a slower growth of concentration fluctuations in the early stage of spinodal decomposition. Gelles and Frank also illustrated the increasing segregation of polymer blends holding at elevated temperatures.

Multilayer composite materials are recently gaining increased attention due to the possible advantages of the resulting parts. Multilayer parts allow the integration of functions and the tailored usage of materials. Compared to rotational molded parts made out of one material, weight and cost reduction, enlargement of the fields of applications, and advanced product quality and characteristics are potential advantages of multilayer setups.

For materials in composite parts, sufficient bonding between the materials is the most significant selection criterion. Thereby in state-of-the-art applications and production processes mainly specific adhesion is considered. The possibility to create mechanical bonding could thereby broaden the possible material combinations because it is mostly unaffected by the interactions between the used materials.

In this work, the possibilities of producing multilayer parts by rotational molding are investigated, where the materials used show no relevant specific adhesion to each other. The bonding between the materials was achieved by producing a defined interlayer consisting of a material mix in which undercuts and entanglements between the two materials occur. Besides undercuts and entanglements with connections to the base material, inclusions without connection to the base material occur as well. These inclusions do not contribute to the mechanical adhesion between the materials. The aimed geometrical material interactions are schematically shown in Figure 3.

\section{Experimental}

2.1. Used Materials. Two layered parts with an additional interlayer consisting of a material mix were processed by rotational molding. The outer component was a thermoplastic polyurethane (TPE-U) Elastollan SP 9305 provided by BASF SE (Ludwigshafen, Germany). The second, inner component was a polyethylene medium-density (PE-MD) Lupolen $4021 \mathrm{~K}$ RM Powder provided by LyondellBasell (Rotterdam, Netherland). Both materials were provided in powdery form. 


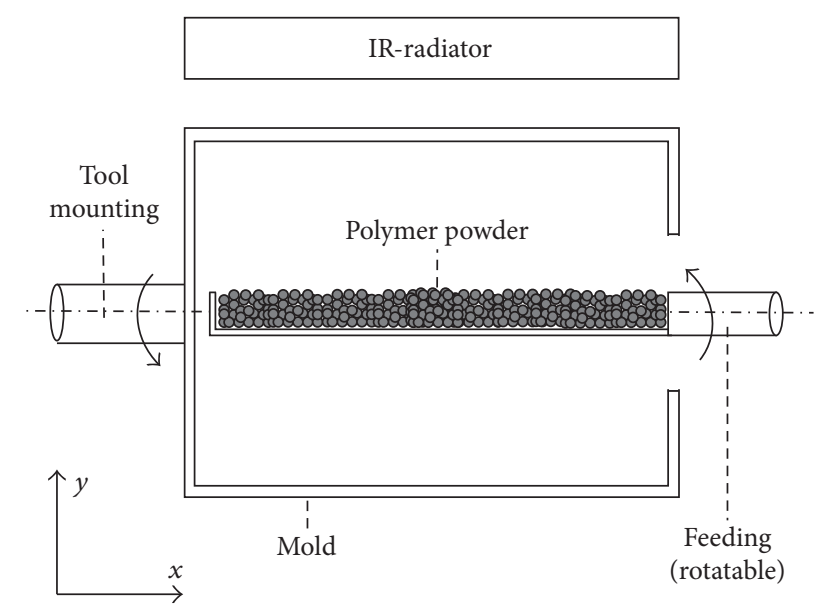

Figure 4: Cross section of the experimental setup (according to [13]).

2.2. Material Characterization. The materials used were characterized by different analysis methods. A differential scanning calorimetry (DSC) (Q 1000 TMDSC, TA Instruments, Delaware, USA) was conducted to analyze the melting and crystallization temperatures. The material was heated up to $220^{\circ} \mathrm{C}$, cooled down to $0^{\circ} \mathrm{C}$, and then heated up again. The heating and cooling rates were set to $10 \mathrm{~K} \mathrm{~min}^{-1}$. The cooling and the second heating process were analyzed. The rheological behavior of the materials was characterized using a rotational viscometer (AR 2000, TA Instruments, Delaware, USA) at a frequency of $1 \mathrm{~Hz}$ and a deformation of $0.05 \%$.

The flow behavior of the powder materials was characterized according to DIN EN ISO 6186 [24] to analyze the pourability of the materials. Therefore a hopper with opening of $15 \mathrm{~mm}$ diameter was used and the outflow time of $150 \mathrm{~g}$ polymeric powder was measured. The particle shape of the powdery materials was characterized using scanning electron microscopy (SEM), detecting the secondary electrons.

\subsection{Rotational Molding Experiments}

2.3.1. General Settings. Rotational molding experiments are conducted using a uniaxial rotating, cylindrical mold with a diameter of $211 \mathrm{~mm}$ and a length of 210. The temperature control system is based on contour-following infrared heaters which are located outside the mold and external compressed air spreading. The mold is set to rotate with a speed of $15 \mathrm{~min}^{-1}$ and provides axial opening which enables the feeding of material at random process times. Rotatable feeding is placed in the center of the rotation axis of the mold that can be moved axially into the mold. By a rotation of the feeding polymeric material can be added to the process and distributed homogenously along the mold length. The temperature of the system is measured by infrared temperature measurement at the outside of the mold. The cross section of the experimental setup (produced by FILL Ges.m.b.H., Austria) is shown schematically in Figure 4.

2.3.2. Processing Protocol. First, polyethylene is placed in the cold mold. Then the mold is heated up to processing

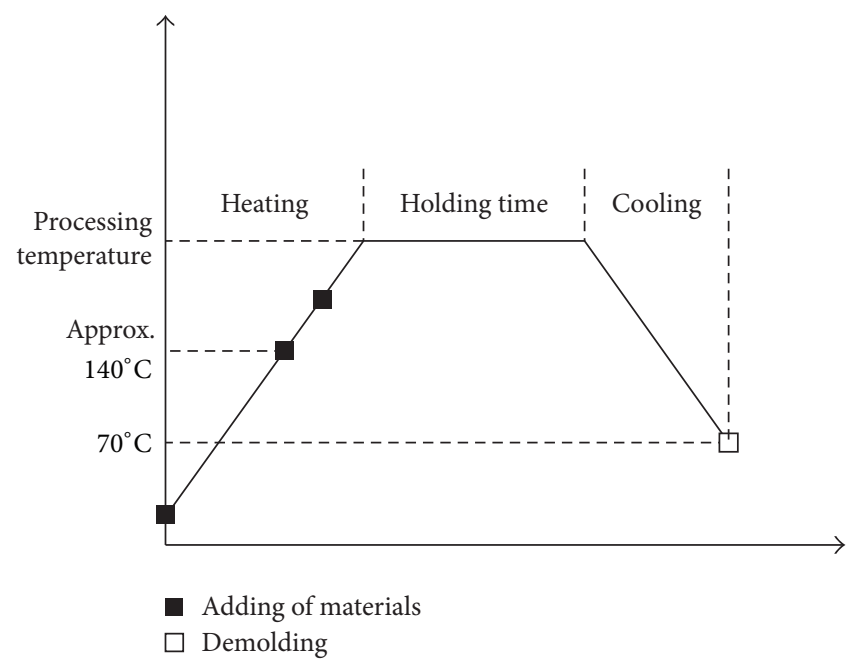

FIGURE 5: Temperature profile used for the rotational molding experiments.

temperature for all experiments which takes approximately 12 minutes. After the polyethylene is completely spread over the mold surface and a homogenous melt layer is formed, a powdery PE/TPE-U mixture is added at a mold temperature of approximately $140^{\circ} \mathrm{C}$. After spreading and melting of the material mix, a single material TPE-U layer is added. The mold is then set to hold the temperature at processing temperature for a defined time before cooling it to $70^{\circ} \mathrm{C}$ and demolding the part. The temperature profile is schematically shown in Figure 5.

The amount of neat material is set constant to generate TPE-U and PE-MD layers of a theoretical thickness of $0.75 \mathrm{~mm}$. Several test series are conducted, varying different process parameters as described below.

First, the amount of the material mix and the composition of the contained materials are varied. For the variation of the amount of interlayer material, thicknesses between $0.375 \mathrm{~mm}$ and $1.0 \mathrm{~mm}$ with $0.125 \mathrm{~mm}$ steps in between are aimed at, based on volumetric calculations. The composition of the interlayer is here set constant to 50 vol.-\% TPE-U and 50 vol.$\% \mathrm{PE}-\mathrm{MD}$. For the variation of the interlayer composition, the aimed thickness of the layer is set constant to $0.75 \mathrm{~mm}$. The composition of the material mix is varied between 10 vol.$\%$ and 90 vol.- $\%$ TPE-U in 10 vol.-\% steps. Additionally, variations of the processing temperature and the holding time are conducted. The processing temperature is varied between $160^{\circ} \mathrm{C}$ and $220^{\circ} \mathrm{C}$ in $20 \mathrm{~K}$ steps and the holding time is varied as well, between $0 \mathrm{~s}$ and $1800 \mathrm{~s}$ with intermediate steps of $450 \mathrm{~s}$ and $900 \mathrm{~s}$. The thickness of the interlayer is here set constant to $0.75 \mathrm{~mm}$ and the composition of the interlayer to an equal volumetric distribution of TPE-U and PE-MD. An overview over the conducted experiments is given in Table 1.

Besides the rotational molding experiments with an integrated interlayer consisting of a material mixture, corresponding experiments without an interlayer are conducted as well. Here, a two-layer built-up, polyethylene on the outside and thermoplastic polyurethane on the inside, is processed 
TABLE 1: Overview of the conducted experimental design.

\begin{tabular}{|c|c|c|c|c|}
\hline Test series & $\begin{array}{l}\text { Theoretical } \\
\text { thickness of } \\
\text { interlayer [mm }]\end{array}$ & $\begin{array}{c}\text { Interlayer } \\
\text { composition } \\
\text { vol.-\% } \\
\text { PE : vol.-\% } \\
\text { TPE-U }\end{array}$ & Processing temperature $\left[{ }^{\circ} \mathrm{C}\right]$ & $\begin{array}{l}\text { Holding time at } \\
\text { processing } \\
\text { temperature }[\mathrm{s}]\end{array}$ \\
\hline Variation of interlayer thickness & $0.375-1.125$ & $50: 50$ & 200 & 900 \\
\hline Variation of interlayer composition & 0.75 & $10: 90-90: 10$ & 200 & 900 \\
\hline Variation of processing temperature & 0.75 & $50: 50$ & $160-220$ & 900 \\
\hline Variation of holding time & 0.75 & $50: 50$ & 200 & $0-1800$ \\
\hline
\end{tabular}

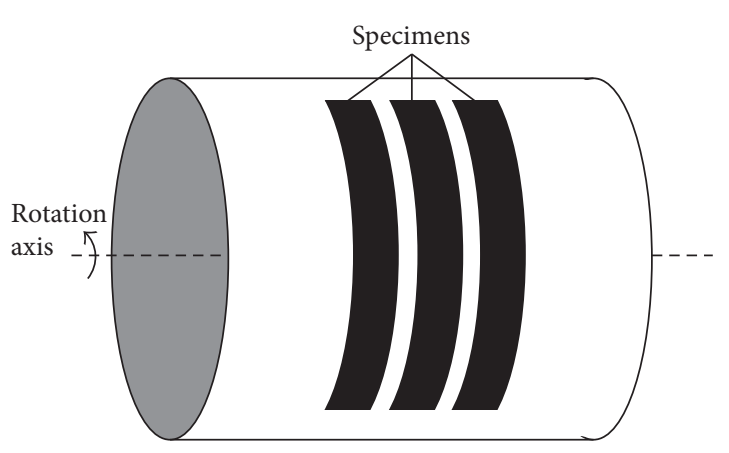

FIGURE 6: Position of specimens on the rotationally molded sample.

at a processing temperature of $200^{\circ} \mathrm{C}$, a holding time of 900 seconds and a layer thickness of $1 \mathrm{~mm}$ each.

2.4. Sample Testing. The bonding strength of the multilayer composites is measured at $23^{\circ} \mathrm{C}$ using tensile tests. Therefore, samples with a length of $250 \mathrm{~mm}$ and a width of $25 \mathrm{~mm}$ are cut out of the cylindrical parts in the direction of rotation as shown in Figure 6.

The components are separated at one side of the specimen at a length of approximately $50 \mathrm{~mm}$ and the components are then fixed into the chuck jaws of a tensile testing machine as shown in Figure 7. The testing is conducted with a speed of $100 \mathrm{~mm} \mathrm{~min}^{-1}$. The necessary force to peel the samples is analyzed over a length of $200 \mathrm{~mm}$ and the average peeling force is determined. The test is repeated with five samples for each test setting.

The tested samples are analyzed using scanning electron microscopy (SEM) and macroscopic photography analysis with an emphasis on the fracture zone.

\section{Results}

3.1. Material Characterization. In Figure 8 the results of the DSC analysis are shown. The PE-MD shows a melting peak at $126.0^{\circ} \mathrm{C}$ and an enthalpy of crystallization of $146.9 \mathrm{~J} \mathrm{~g}^{-1}$. The crystallization peak was measured at $114.2^{\circ} \mathrm{C}$.

The DSC results for the TPE-U are shown in Figure 9. The TPE-U shows a melting peak at $134.2^{\circ} \mathrm{C}$ and an enthalpy of fusion of $19.3 \mathrm{~J} \mathrm{~g}^{-1}$. The crystallization peak was measured at $112.2^{\circ} \mathrm{C}$.

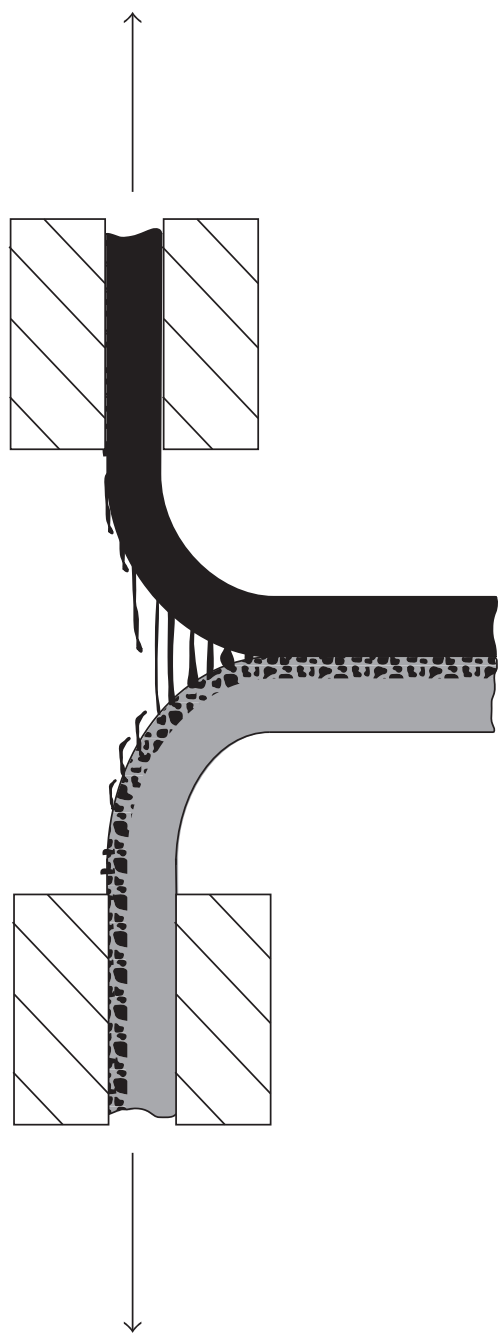

FIGURE 7: Experimental setup for bonding strength measurements.

Both materials show very comparable thermal behavior in regard to the melting and crystallization temperatures, whereas the enthalpy of fusion is much higher for the PE-MD material, which is presumably caused by a higher degree of crystallinity.

The results of the rheological characterization of the two investigated materials are shown in Figure 10. For both materials, the flow resistance decreases with increasing 


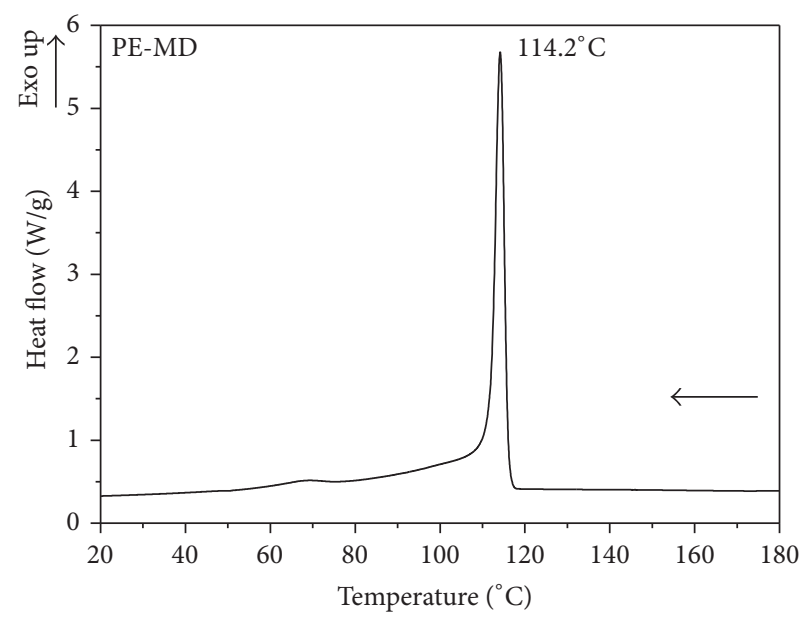

(a)

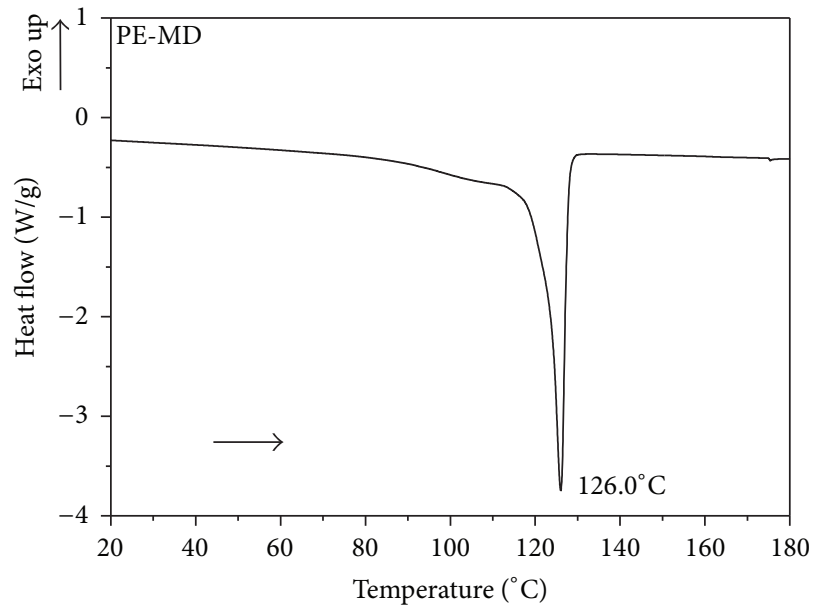

(b)

FIGURE 8: Melting and solidification behavior of PE-MD (Lupolen $4021 \mathrm{~K}$ RM Powder): (a) cooling and (b) second heating.

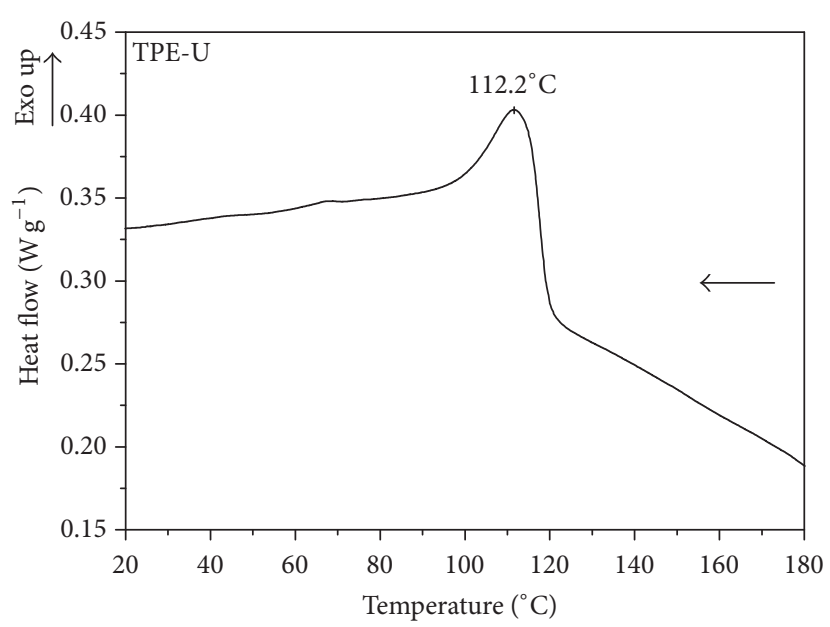

(a)

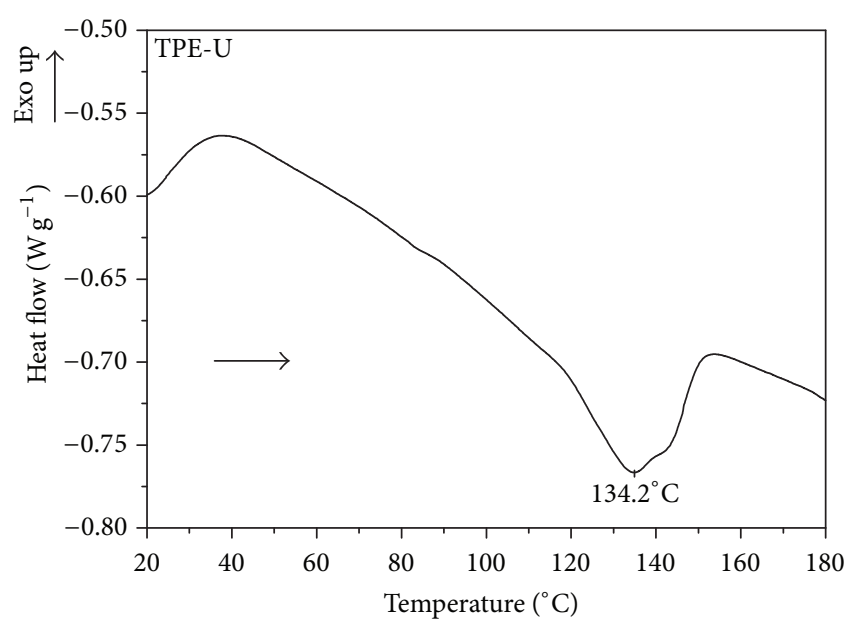

(b)

FIGURE 9: Melting and solidification behavior of TPE-U (Elastollan SP 9305): (a) cooling and (b) second heating.

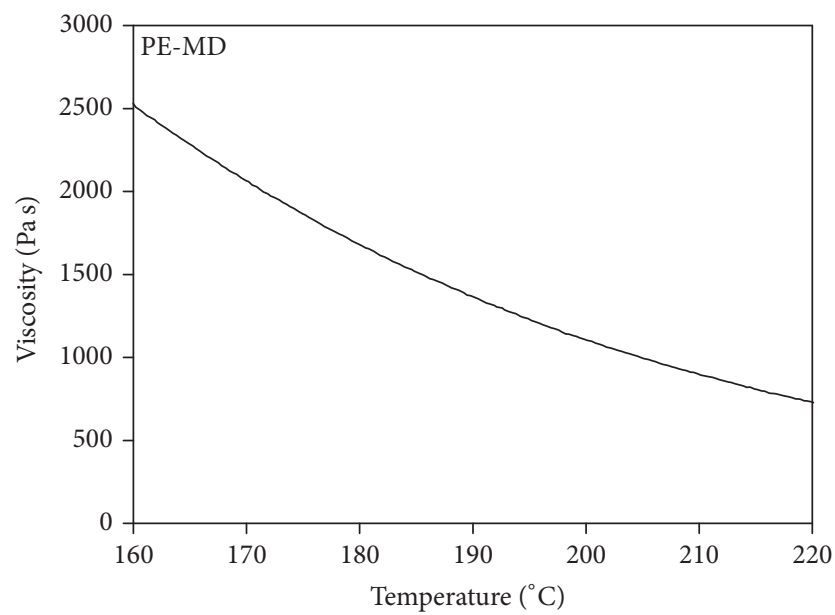

(a)

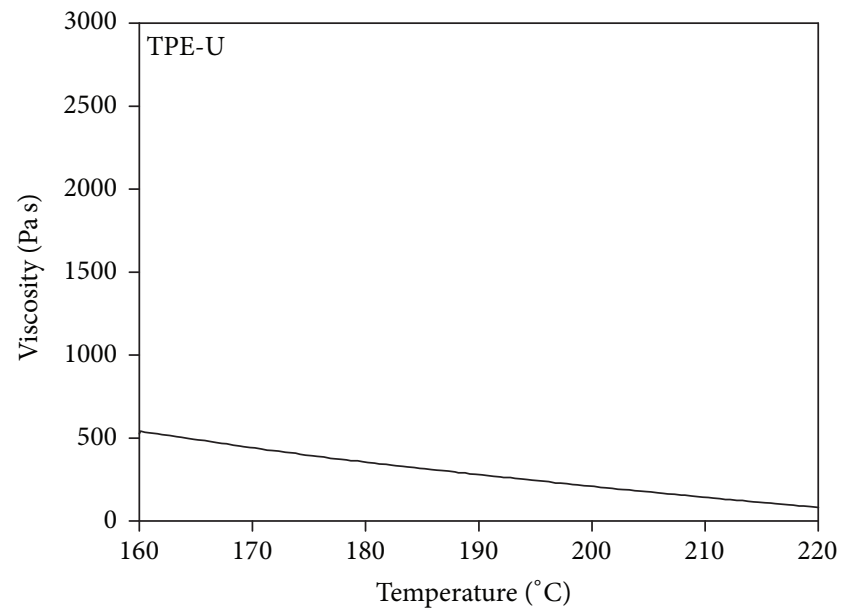

(b)

FIgure 10: Viscosity of the used materials: (a) PE-MD and (b) TPE-U. 


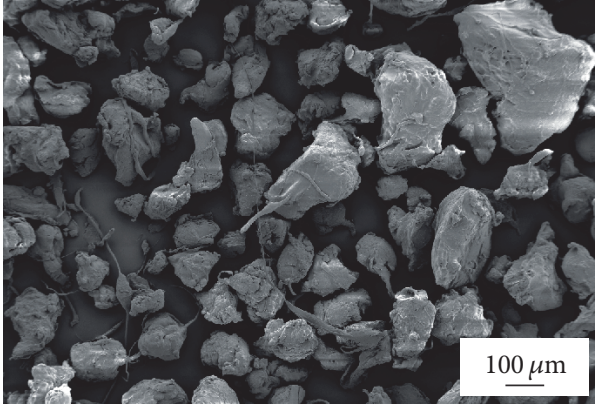

(a)

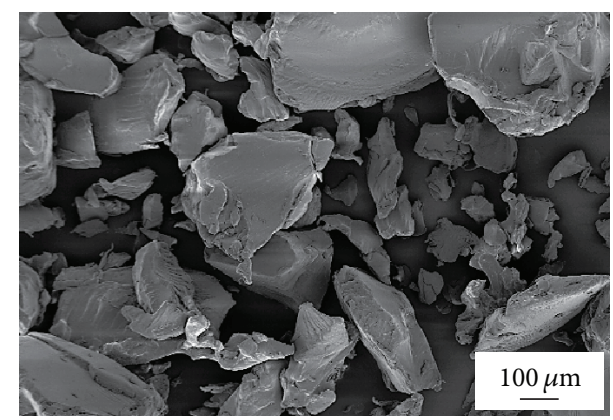

(b)

FIGURE 11: SEM characterization of used materials: (a) PE-MD and (b) TPE-U.
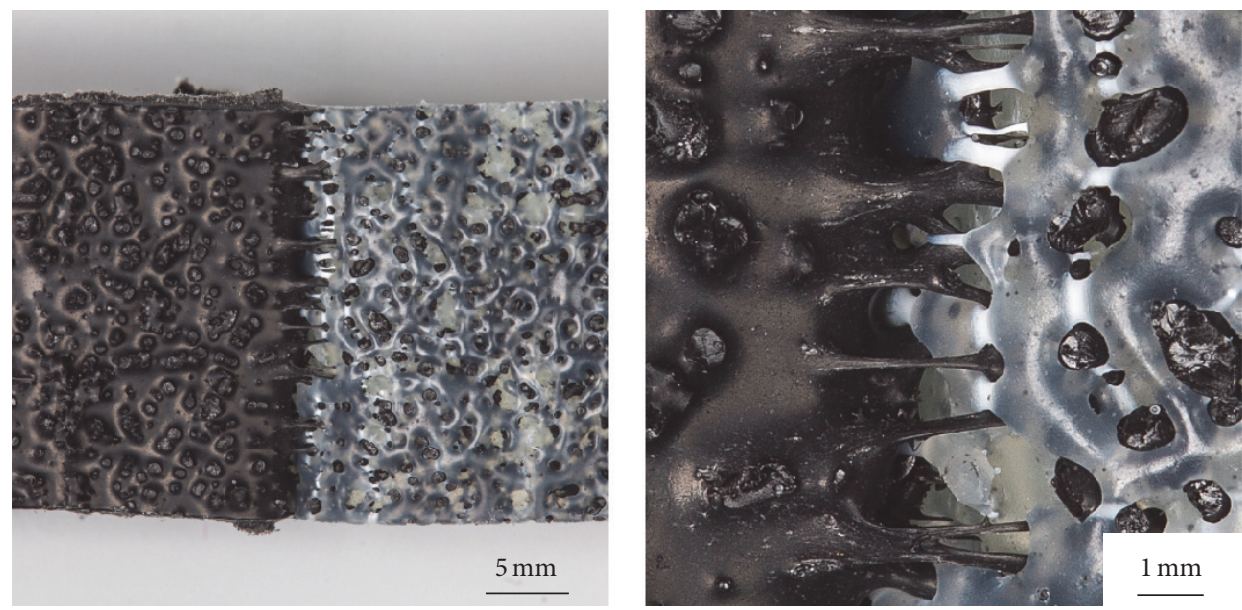

FIGURE 12: Multilayer sample with an interlayer under peeling load and materials: PE-MD (translucent) + TPE-U (black); aimed interlayer thickness: $1.125 \mathrm{~mm}$, processing temperature: $200^{\circ} \mathrm{C}$, holding time: $900 \mathrm{~s}$, and 50 vol.- $\%$ TPE-U in material mixture.

temperature. The PE reveals a viscosity of approx. $2500 \mathrm{~Pa}$ s at $160^{\circ} \mathrm{C}$ which decreases to $727 \mathrm{Pas}$ at $220^{\circ} \mathrm{C}$. The viscosity of the TPE-U is lower for all investigated temperatures. Its flowability ranges from $81.4 \mathrm{Pas}\left(220^{\circ} \mathrm{C}\right)$ to $525 \mathrm{~Pa} \mathrm{~s}\left(160^{\circ} \mathrm{C}\right)$.

The flow behavior measurement according to DIN EN ISO 6186 resulted in times to discharge the hopper of 12 seconds for the polyethylene and 14 seconds for the TPEU. Both materials have a comparable flowability in powdery form with slight better flowability of the PE-MD.

Images of the powder shape, characterized by scanning electron microscopy, are shown in Figure 11. Both materials show mainly compact particles with single threads added to the PE-MD particles.

\subsection{Optical Characterization of Rotational Molded Samples.} In Figure 12, a multilayer rotational molded part with an interlayer consisting of a material mixture is shown under peel load. Entanglements and undercuts of both materials, PE-MD (transparent) and TPE-U (black), are shown. In the interface layer the elongation of single connection points from the base material of the TPE- $U$ to mechanical bonded TPE-U parts can be seen. The failure at the already peeled areas occurred within the TPE-U material by failure of the entanglements and undercuts in the area of the connection to the base material (left picture areas).

In Figure 13, exemplary fracture surfaces are shown with failure of the TPE-U component illustrated on the left side. Approximately circular fractures zones of the TPE-U can be seen surrounded by PE material which does not show indication of fractures. This leads to the conclusion that this is the molded surface layer of the PE-MD. Observation of the dedicated TPE-U layer confirms this assumption. On the right side, a fracture within the PE-MD material is shown. Again, no indication for fractures at the surrounding TPE$\mathrm{U}$ material can be observed. In contrast to the fracture of the TPE-U, remaining deformation of the failed PE-MD components occurred.

No material remaining at the respective other layer was detected for parts produced without a multiphase interlayer. The fracture surface showed no indications for adhesion between the material layers. No mechanical interlocks occurred. Mechanical testing of the sample was not possible due to insufficient adhesion to each other. Thus, the specific adhesion can be neglected for the characterized material combination. Figure 14 shows the fracture behavior in dependency of the theoretical interlayer thickness at the top left (Figure 14(a)). At a theoretical layer thickness of $0.5 \mathrm{~mm}$ 


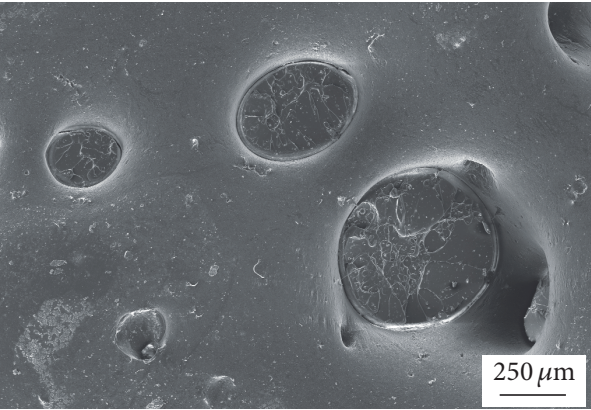

(a)

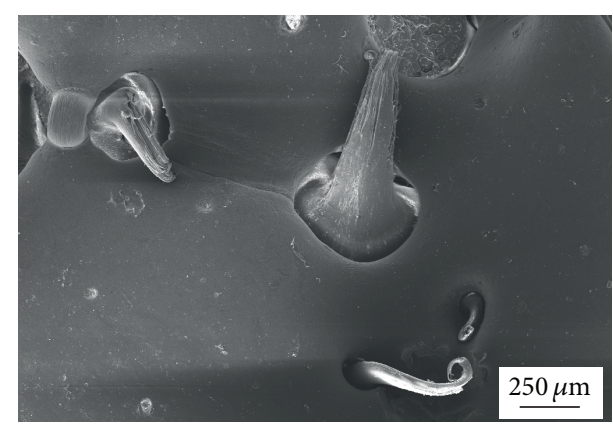

(b)

FIGURE 13: SEM analysis of the failure behavior at exemplary samples: (a) failure within the TPE-U component and (b) failure within the PE component.

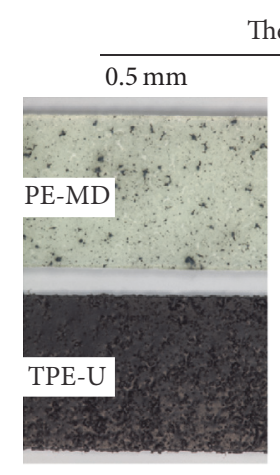

Theoretical interlayer thickness

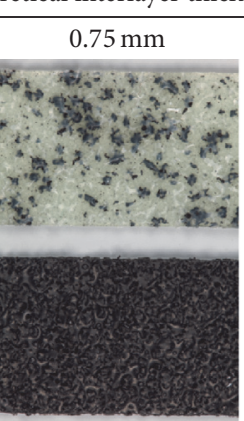

(a)

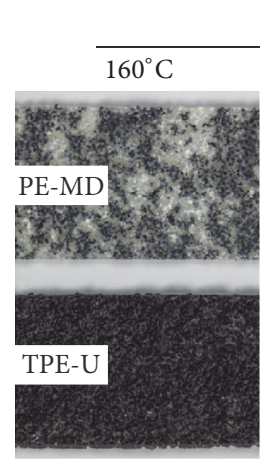

Processing temperature

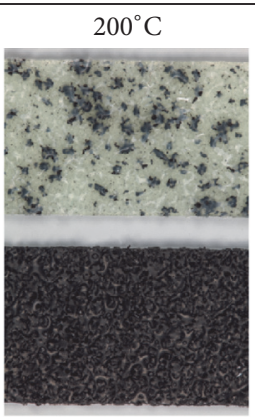

(c)

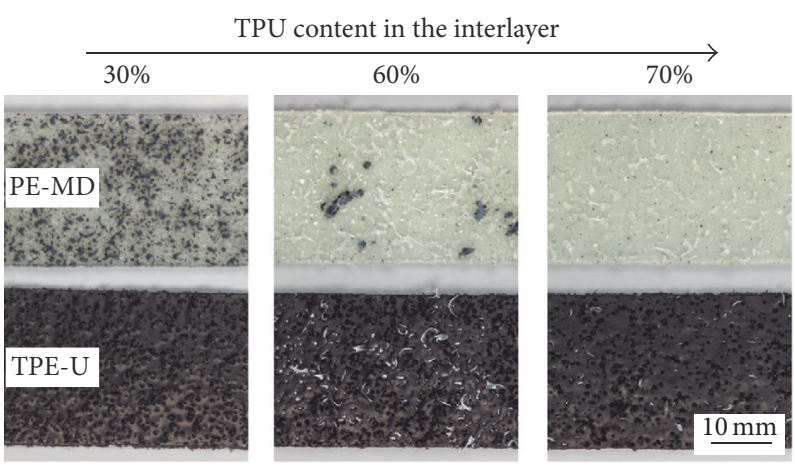

(b)

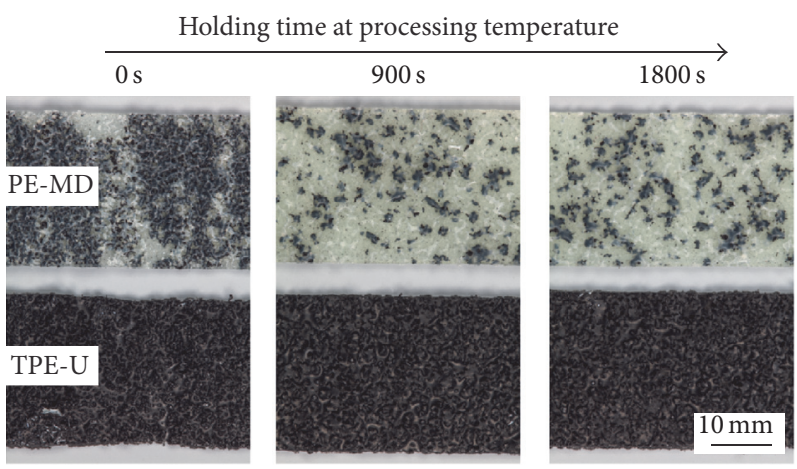

(d)

FIGURE 14: Fracture surface in dependency of the processing parameters interlayer thickness (a), interlayer composition (b), processing temperature (c), and holding time at processing temperature (d).

only single TPE-U parts remain at the PE-MD layer. These are partly inclusions, completely surrounded by PE-MD. For higher theoretical interlayer thicknesses, the amount of TPE-U remaining in the PE-MD layer increases significantly. Additionally, for all interlayer thicknesses nearly no PE-MD material was detected in the TPE-U layer. The fracture took place only within the TPE-U material. The fracture behavior for different interlayer compositions is illustrated on the right side in the top picture area (Figure 14(b)). For a TPE-U content of 30 vol.- $\%$, TPE-U components remain in the PE$\mathrm{MD}$ layer, while no PE-MD components remain in the TPE-U layer. For a TPU content of 60 vol.- $\%$ in both layers particles of the respective other material can be found. For 70 vol.$\%$ TPE- $\mathrm{U}$ in the interlayer, nearly only PE-MD components were found in the TPE-U layer.

For all processing temperatures, nearly only TPE-U material rests remain in the PE-MD layer, while no relevant left behinds of the PE-MD were observed in the TPE-U layer. The amount of TPE- $U$ thereby decreases significantly with increasing processing temperature. The fracture behavior in dependency of the processing temperature is shown in Figure 14(c). In Figure 14(d) the fracture behavior is shown in dependency of the holding time at processing temperature. The resulting fracture behavior is comparable to the variation 


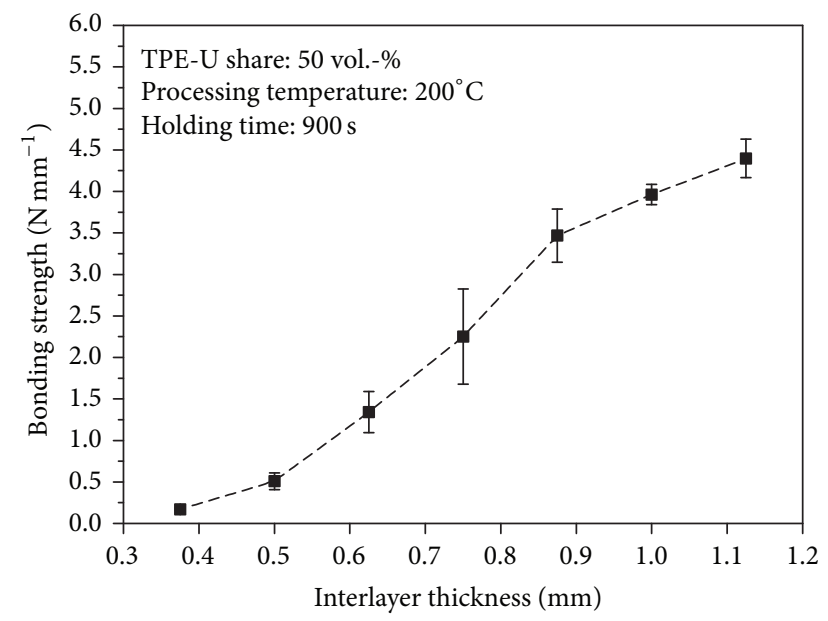

FIGURE 15: Influence of the interlayer thickness on the resulting bonding strength.

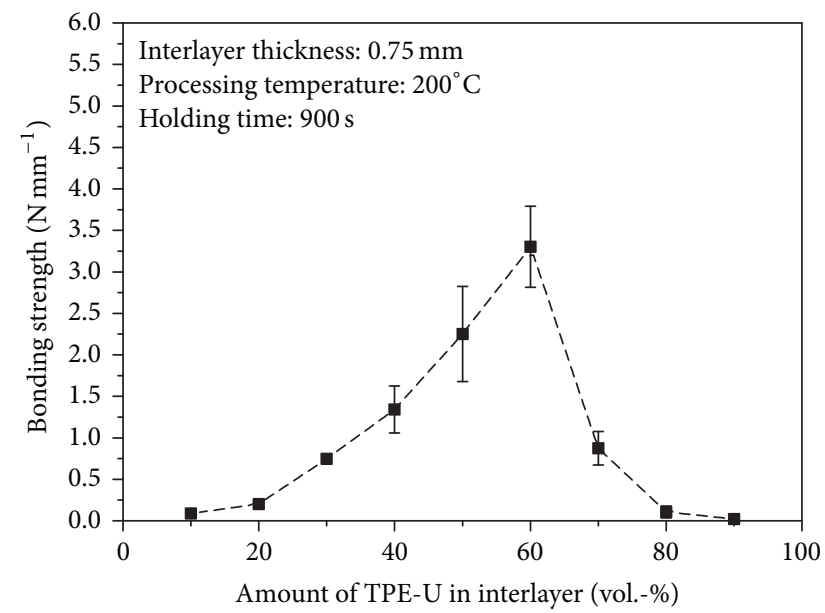

FIGURE 16: Influence of the material mixture composition on the resulting bonding strength.

of the processing temperature. No remaining PE-MD in the TPE-U layer was observed whereas the amount of TPE- $U$ in the PE-MD layer decreases with increasing holding time.

3.3. Bonding Strength. The influence of the theoretical interlayer thickness (resp., the amount of material mixture) on the resulting bonding strength is shown in Figure 15. The bonding strength increases with increasing thickness of the interlayer from $0.17 \mathrm{~N} \mathrm{~mm}^{-1}(0.375 \mathrm{~mm})$ to $4.40 \mathrm{~N} \mathrm{~mm}^{-1}(1.125 \mathrm{~mm})$. The bonding strength and the interlayer thickness show an approximately linear correlation.

The influence of the material mixture composition is shown in Figure 16. The bonding strength increases up to a TPE-U percentage of $60 \mathrm{Vol} .-\%$ where a maximum of about $3.5 \mathrm{~N} \mathrm{~mm}^{-1}$ was observed. The bonding strength decreases for TPE-U shares above 60 vol.- $\%$.

In Figure 17, the bonding strength in respect to the investigated processing temperatures is shown. The bonding

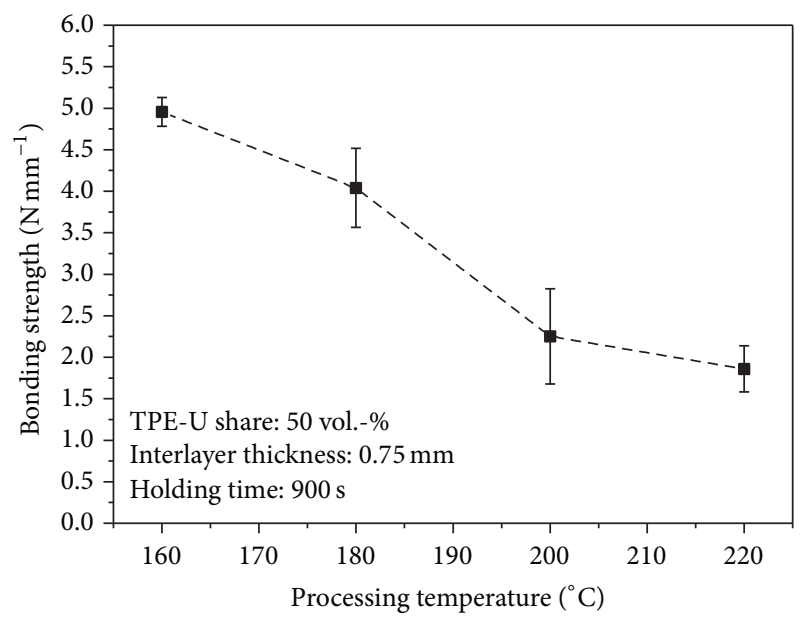

FIGURE 17: Influence of the processing temperature on the resulting bonding strength.

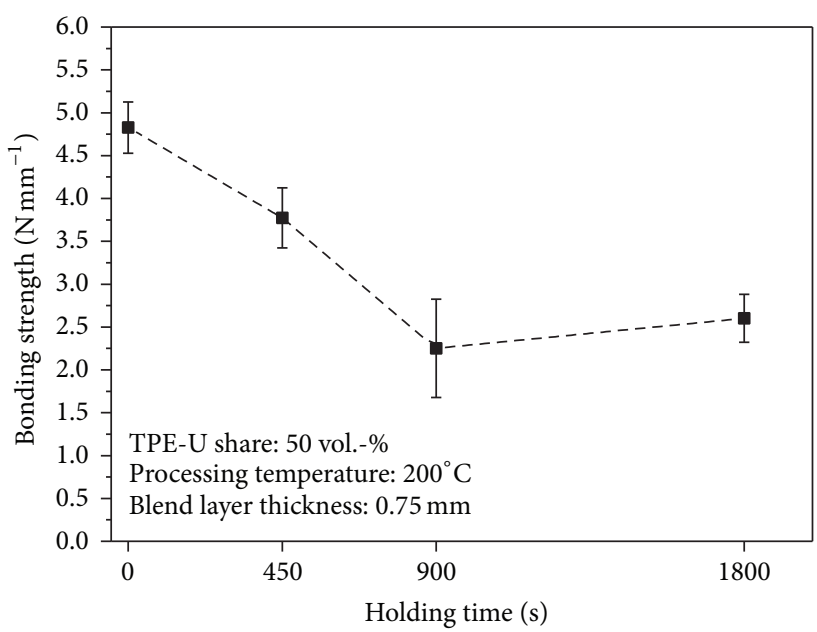

FIGURE 18: Influence of the holding time at processing temperature on the resulting bonding strength.

strength decreases with increasing temperature from approximately $5.0 \mathrm{~N} \mathrm{~mm}^{-1}\left(160^{\circ} \mathrm{C}\right)$ to $1.9 \mathrm{~N} \mathrm{~mm}^{-1}\left(220^{\circ} \mathrm{C}\right)$.

Figure 18 shows the bonding strength for different holding times of the polymeric melts at processing temperature of $200^{\circ} \mathrm{C}$. The bonding strength decreases from $4.8 \mathrm{~N} \mathrm{~mm}^{-1}$ (no holding time) to $2.3 \mathrm{~N} \mathrm{~mm}^{-1}$ (900 seconds). No further reduction was observed to a holding time of 1800 seconds.

\section{Discussion}

4.1. Material Characterization. The material characterization reveals good comparison of the two used materials. The melting peak temperature differs by approx. $8 \mathrm{~K}$ and the flowability according to DIN EN ISO 6186 differs by about 2-second outflow time. Additionally, the particles showed a comparable shape. Therefore, it can be assumed that the melting and sintering behaviour and the behaviour in powdery form are comparable. Segregation effects during 
rotation and sintering are therefore not to be expected and a statistically random distribution of the materials in the multiphase interlayer is assumed. The behaviour in the melt state differs between both materials due to the lower viscosity of the TPE-U compared to the PE-MD.

4.2. Influence of Multimaterial Interlayer. For the characterized multilayer components, peel strengths up to $5 \mathrm{~N} \mathrm{~mm}^{-1}$ were measured. If the peel strength measured was in the range of the maximum values reached $\left(5 \mathrm{~N} \mathrm{~mm}^{-1}\right)$, a specific failure behaviour could be identified. Here, the failure took place within the respective base materials in the area of entanglements and undercuts as shown in Figure 14. For the same material combination without interlayer, a separation of the layers took part without any failure within the base materials. Here, the forces needed to separate these layers were too low to characterize. Therefore, it can be deducted that mechanical adhesion is mainly responsible for the bonding strength characterized for parts with a multimaterial interlayer. The general feasibility of generating mechanical adhesion in multilayer rotational molded parts could therefore be proven.

4.3. Influence of the Interlayer Thickness (Resp., Amount of Material Mixture). An increased interlayer thickness presumably leads to a higher percentage of undercuts and entanglements between the two materials due to the potentially thicker interaction thickness in which both materials are present. This leads to improved mechanical adhesion and therefore to a higher bonding strength. This effect is also illustrated in Figure 14. For all interlayer thicknesses, the failure occurs within the TPE-U. For an interlayer thickness of $0.500 \mathrm{~mm}$ only few undercuts and entanglements are present which are destroyed during testing and remain in the PEMD layer. With increasing layer thickness, more connection points for mechanical adhesion build up which are then destroyed during peeling test. This can be seen by the increasing amount of TPE-U components remaining in the PE layer for $0.750 \mathrm{~mm}$ and $1.125 \mathrm{~mm}$ aimed interlayer thickness. The higher amount of mechanical connection points which are destroyed during peeling leads to an increasing bonding strength.

4.4. Influence of Material Mixture Composition. A volumetric parity of the materials in the interlayer presumably allows for an equal quantity of entanglements and undercuts for both materials what leads to comparable areas which can be utilized to transfer stresses from the base material into the interlayer. A lower volumetric share of one component within the interlayer could lead to fewer structures contributing to mechanical adhesion. A lower bonding strength, due to failure in this component at lower peeling stresses, is the result. A shift of the maximum bonding strength to other shares than 50 vol.- $\% / 50$ vol.- $\%$ as shown in Figure 16 occurs due to the different mechanic properties of the materials. Tensile stress, strain at break, and the elastic modulus are material parameters which potentially influence the optimum share with a maximum in bonding strength. In the illustrated combination of TPE-U and PE-MD the maximum bonding strength was measured at 60 vol.- $\%$ TPE-U. This correlation can also be reconstructed in the failure behavior and in the resulting fracture patterns as shown in Figure 14. For lower TPE-U contents within the interlayer, the failure takes place only in the TPE-U component. Various TPE-U inclusions and broken undercuts/entanglements remain in the PE-MD component. At the material mixture composition with the highest bonding strength (40 vol.-\% PE-MD, 60 vol.-\% TPE$\mathrm{U})$, the fracture takes place in both components which is an indication that both components withstand comparable stresses within the interlayer. In this case cohesive failure occurs in both materials that results in remaining of both materials on the respective other layer. For higher TPE$\mathrm{U}$ contents, the fracture is initiated by breaking or pulling out of PE-MD undercuts and entanglements. Here PE-MD components remain in the TPE-U layer.

The fracture behavior correlates with the measured bonding strength. The cohesive failure takes place in the material which can transmit lower forces to the respective base material layer. The material composition within the multimaterial interlayer is mainly responsible for the failure behavior.

4.5. Influence of the Processing Temperature. The influence of processing temperature can presumably be tracked back to segregation effects during the time the materials are in the melt state as shown by Gelles and Frank [23]. Surface tension effects result in forces which lead to a decrease of the relative surface of a material. These forces result in segregation of incompatible materials. Due to the temperature dependency of the viscosity, which decreases with increasing temperature as shown in Figure 10, these segregation effects accelerate at higher temperatures due to the lower flow resistance at higher temperatures. Figure 14 illustrates this correlation. For a processing temperature of $160^{\circ} \mathrm{C}$, (Figure $14(\mathrm{c})$ ) a thinly dispersed material mixture can be observed which results in a high number of undercuts and entanglements. These mechanical connection points fail under peeling stress and TPE-U components remain in the PE layer. With an increasing processing temperature, the mixture becomes coarser. This results in fewer mechanical connection points between the two materials and therefore in the decrease of bonding strength at higher processing temperatures (Figure 17).

4.6. Influence of the Holding Time at Processing Temperature. Longer holding times lead to increased segregation due to longer times in which these, presumably surface tension driven, effects can take place. Corresponding to the effects by increased processing temperatures [22], this segregation effect results in fewer undercuts and entanglements what decreases the resulting bonding strength. This effect is also illustrated in Figure 14. For a holding time of 0 seconds (Figure $14(\mathrm{~d})$ ) a thinly dispersed material mixture can be seen which results in a high number of undercuts and entanglements. These mechanical connection points fail under peeling stress and TPE-U components remain in the PE-MD layer. With increasing holding time at processing temperature the mixture becomes coarser. This results in fewer mechanical 
connection points between the two materials and less TPE-U remaining in the $\mathrm{PE}-\mathrm{MD}$ layer.

\section{Conclusion}

In this work, the general feasibility of generating multilayer parts in rotational molding out of materials which are incompatible regarding specific adhesion was proven. This was accomplished by the build-up of a defined layer setup incorporating a multimaterial interlayer between two compact layers. Mechanical adhesion caused by undercuts and entanglements between the materials used (TPE-U and $\mathrm{PE})$ was created. The present mechanisms of adhesion were illustrated by imaging techniques and analyzed mechanically by peeling tests.

A parameter variation was conducted, varying the interlayer thickness (resp., amount of material mixture), composition of the material mix, the processing temperature, and holding time. It was shown that the bonding strength increases with increasing interlayer thickness and decreases at higher processing temperatures and longer holding times at processing temperature. For the composition of the mixture a maximum appeared at a TPE-U amount of 60 vol.- $\%$. The bonding strength decreased for higher and lower TPE-U contents. These effects on the bonding strength were correlated with the respective failure behavior which was illustrated by imaging techniques. Thus, the basic correlation between the relevant process parameters, the interlayer formation, and the resulting bonding strength were revealed.

\section{Competing Interests}

The authors declare that there is no conflict of interest regarding the publication of this paper.

\section{Acknowledgments}

This project has received funding from the European Union's Horizon 2020 Research and Innovation Program under Grant Agreement no. 645987.

\section{References}

[1] R. J. Crawford and J. L. Throne, Rotational Molding of Plastics, vol. 2, Research Studies Press Limited, Taunton, UK, 1997.

[2] R. J. Crawford, A. G. Spence, M. C. Cramez, and M. J. Oliveira, "Mould pressure control in rotational moulding," Proceedings of the Institution of Mechanical Engineers, Part B: Journal of Engineering Manufacture, vol. 218, no. 12, pp. 1683-1693, 2004.

[3] A. G. Spence and R. J. Crawford, "The effect of processing variables on the formation and removal of bubbles in rotationally molded products," Polymer Engineering and Science, vol. 36, no. 7, pp. 993-1009, 1996.

[4] R. J. Crawford and M. B. Kearns, Practical Guide to Rotational Moulding, Rapra Technology Limited, Shawbury, UK, 2003.

[5] R. J. Crawford and J. L. Throne, Rotational Molding Technology, William Andrew Publishing, New York, NY, USA, 2002.
[6] M. Kontopoulou and J. Vlachopoulos, "Melting and densification of thermoplastic powders," Polymer Engineering and Science, vol. 41, no. 2, pp. 155-169, 2001.

[7] M. Löhner and D. Drummer, "The effect of pressure variations on the formation of gas inclusions in the rotational molding process," Journal of Polymer Engineering, vol. 35, no. 5, pp. 481491, 2015.

[8] K. Duffy, Method for forming expanded rotomolded products, U.S. Patent, 4,952,350, USA, 1990.

[9] E. Archer, E. Harkin-Jones, M. P. Kearns, and A.-M. Fatnes, "The rotational molding characteristics of metallocene polyethylene skin/foam structures," Journal of Cellular Plastics, vol. 43, no. 6, pp. 491-504, 2007.

[10] S.-J. Liu and C.-H. Yang, "Rotational molding of two-layered polyethylene foams," Advances in Polymer Technology, vol. 20, no. 2, pp. 108-115, 2001.

[11] J. Olinek, C. Anand, and C. T. Bellehumeur, "Experimental study on the flow and deposition of powder particles in rotational molding," Polymer Engineering and Science, vol. 45, no. 1, pp. 62-73, 2005.

[12] H. Sakaki, E. Takasima, S. Matsuda, and H. Kishi, "Polyethylene/polypropylene multilayer rotational molding," Journal of the Adhesion Society of Japan, vol. 46, pp. 473-478, 2010.

[13] M. Löhner and D. Drummer, Multi-layer Rotational Molding of PE-PA Utilizing a Multiphase Interlayer to Generate Mechanical Adhesion, SPE ANTEC, Indianapolis, Ind, USA, 2016.

[14] G. W. Ehrenstein, Handbuch Kunststoff-Verbindungstechnik, Carl Hanser, Munich, Germany, 2004.

[15] G. Habenicht, Kleben: Grundlagen, Technologien, Anwendungen, vol. 3, Springer, Berlin, Germany, 1997.

[16] A. D. McNaugth and A. Wilkinson, IUPAC Compendium of Chemical Terminology, Blackwell Scientific Publications, Oxford, UK, 2nd edition, 1997.

[17] J. W. Cahn and J. E. Hilliard, "Free energy of a nonuniform system. I. Interfacial free energy," The Journal of Chemical Physics, vol. 28, no. 2, pp. 258-267, 1958.

[18] P. Pincus, "Dynamics of fluctuations and spinodal decomposition in polymer blends. II," The Journal of Chemical Physics, vol. 75, no. 4, pp. 1996-2000, 1981.

[19] P. G. de Gennes, "Dynamics of fluctuations and spinodal decomposition in polymer blends," The Journal of Chemical Physics, vol. 72, no. 9, pp. 4756-4763, 1980.

[20] K. Binder, "Collective diffusion, nucleation, and spinodal decomposition in polymer mixtures," The Journal of Chemical Physics, vol. 79, no. 12, pp. 6387-6409, 1983.

[21] I. C. Henderson and N. Clarke, "Two-step phase separation in polymer blends," Macromolecules, vol. 37, no. 5, pp. 1952-1959, 2004.

[22] K. Luo, W. Gronski, and C. Friedrich, "Viscoelastic phase separation in polymer blends," European Physical Journal E, vol. 15, no. 2, pp. 177-187, 2004.

[23] R. Gelles and C. W. Frank, "Effect of molecular weight on polymer blend phase separation kinetics," Macromolecules, vol. 16, no. 9, pp. 1448-1456, 1983.

[24] "Kunststoffe-Bestimmung der Rieselfähigkeit," DIN EN ISO 6186:1998-08, 1998. 

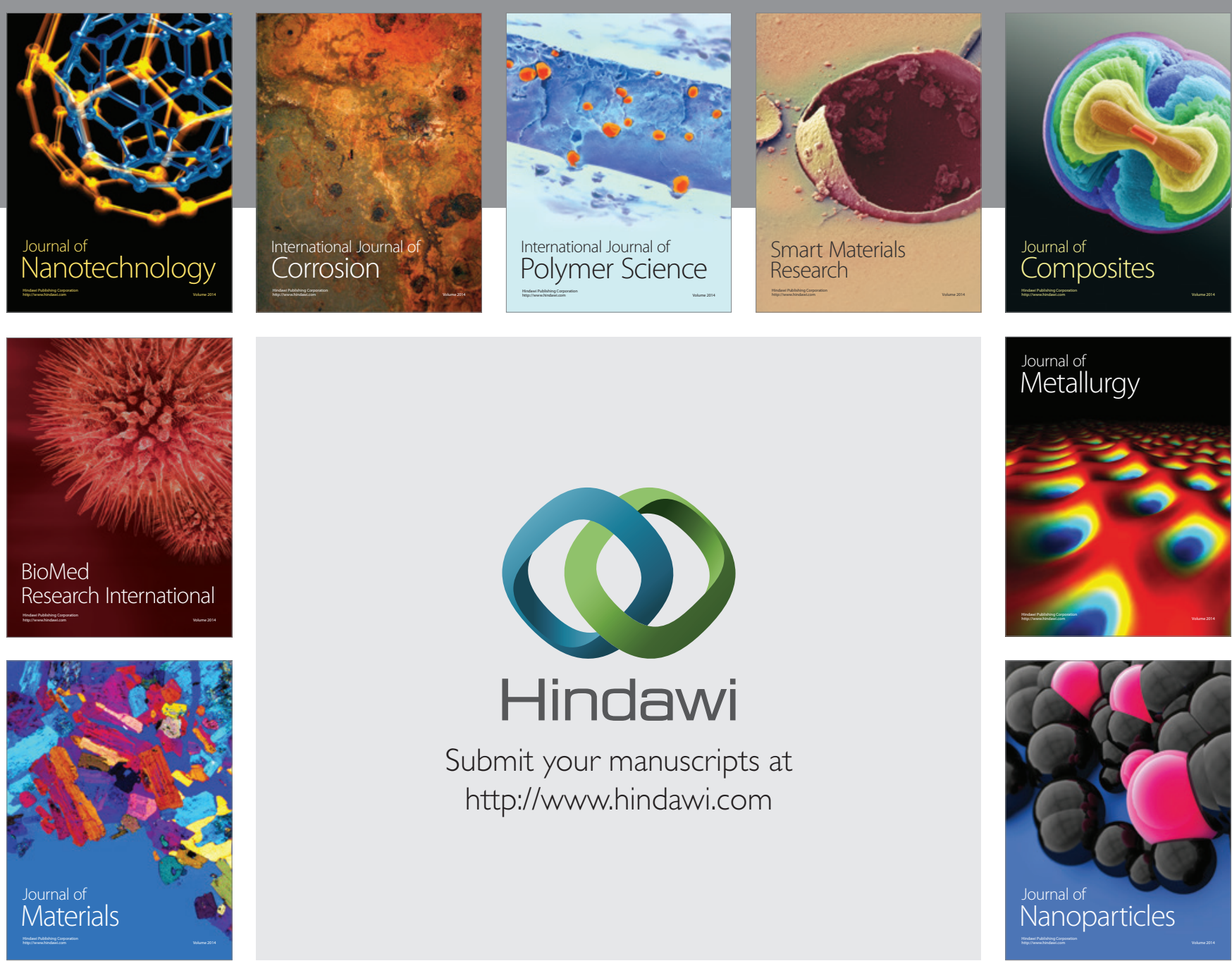

\section{Hindawi}

Submit your manuscripts at

http://www.hindawi.com

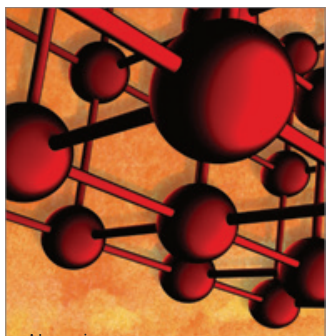

Materials Science and Engineering
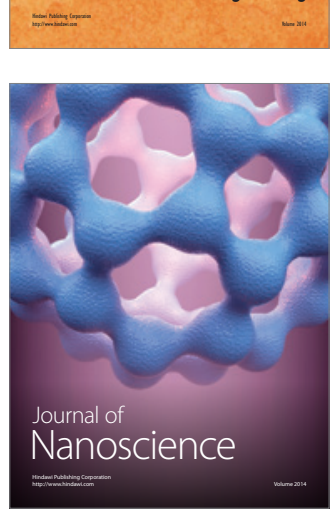
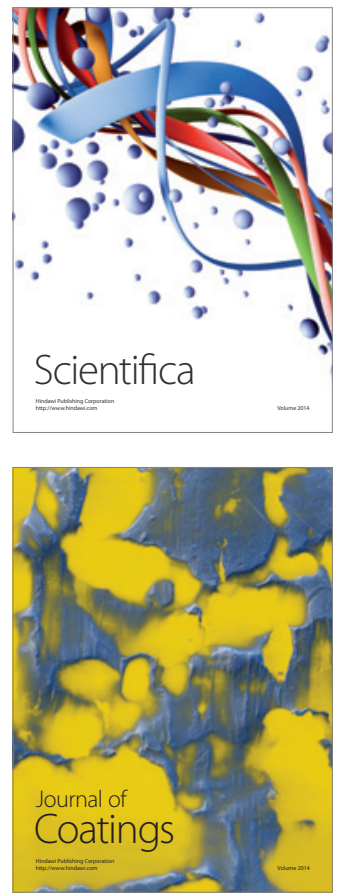
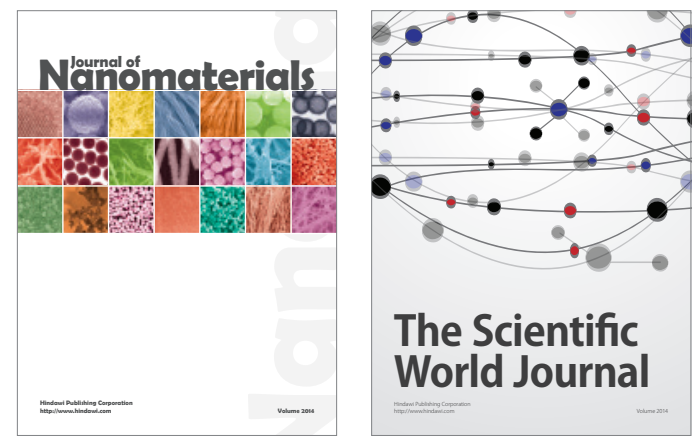

The Scientific World Journal
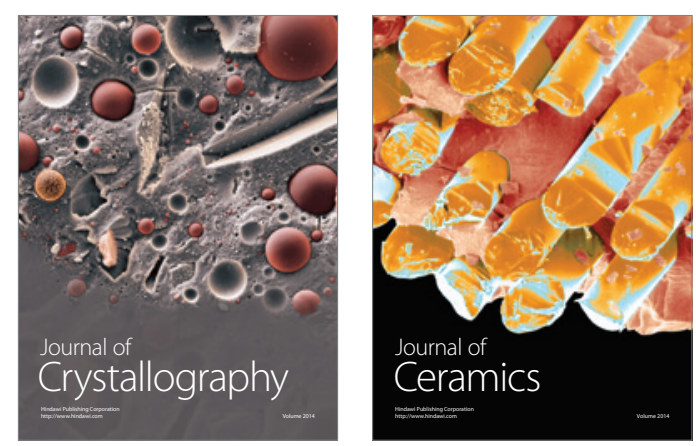
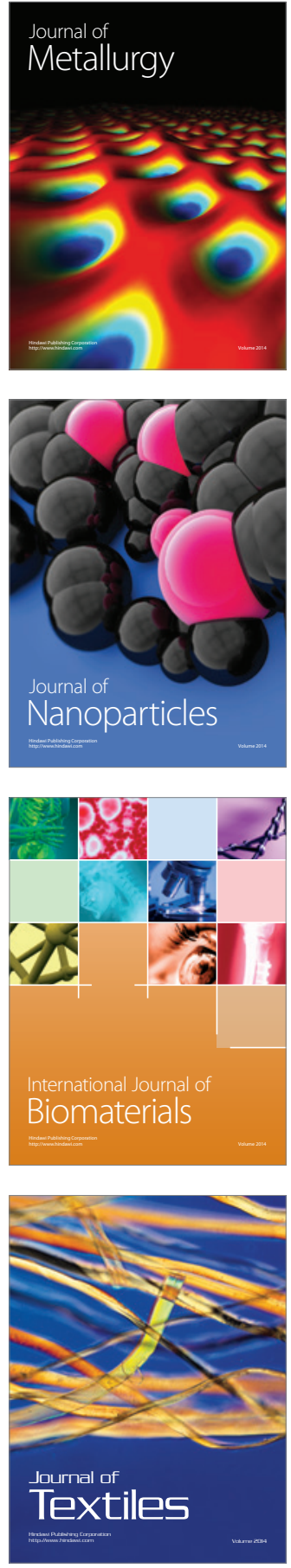